\title{
LA EMBLEMÁTICA
}

\section{EN LA MITOLOGÍA DIDÁCTICA:}

ALCIATO EN BALTASAR DE VITORIA A TRAVÉS DE FRANCISCO VÉLEZ DE ARCINIEGA

\author{
EMBLEMATICS IN DIDACTIC MYTHOLOGY: ALCIATO IN BALTASAR \\ DE VITORIA THROUGH FRANCISCO VÉLEZ DE ARCINIEGA
}

\author{
Alejandro Martínez Sobrino \\ Universidad del País Vasco \\ http://orcid.org/0000-000 I-6958-4604
}

ABSTRACT • Following the path outlined in «La emblemática subsidiaria de la mitología didáctica: Alciato en El Teatro de los Dioses de la Gentilidad», this study analyzes the role played by Francisco Vélez de Arciniega's Historia de los animales mas recebidos en el uso de la medicina as a mediator between Alciato's Emblemata and Baltasar de Vitoria's El Teatro de los Dioses de la Gentilidad.

KEYWORDS: Alciato; Baltasar de Vitoria; Francisco Vélez de Arciniega; Author; Auctor, Authorial; Authority; Auctoritas; Intertextuality; Influence; Translation; Version.

RESUMEN • Continuando con la senda trazada en «La emblemática subsidiaria de la mitología didáctica: Alciato en El Teatro de los Dioses de la Gentilidad», este trabajo estudia el papel que juegan Francisco Vélez de Arciniega y su Historia de los animales mas recebidos en el uso de la medicina como mediadores entre los Emblemata de Alciato en El Teatro de los Dioses de la Gentilidad de Baltasar de Vitoria. ${ }^{1}$

PALABRAS CLAVES: Alciato, Baltasar de Vitoria, Francisco Vélez de Arciniega; Autor; Auctor; Autoridad; Auctoritas; Intertextualidad; Influencia; Traducción, Versión.

1. Este trabajo se enmarca dentro del GIU 19/64: Sociedad, Poder y Cultura en Roma, s. III a. e. - s. III d. e., SPCUR. 
En una ocasión anterior (Martínez Sobrino y García Román, 2020) realizamos un análisis del papel subsidiario que posee la emblemática, en especial los Emblemata de Alciato, en Baltasar de Vitoria y su Theatro de los Dioses de la Gentilidad. Una obra de recopilación mitográfica que su autor publicó en dos partes, 1620, con seis libros (Saturno, Júpiter, Neptuno, Plutón, Apolo y Marte), y 1623, con siete (Mercurio, Hércules, Juno, Minerva, Diana y Venus, y un último sobre dioses menores: la Fortuna, la Fama, etc.). ${ }^{2}$

Decíamos entonces que era más que probable que el monje conociera la obra del abogado milanés a través de los comentarios a la misma ${ }^{3}$ de quien fuera su profesor de Retórica en Salamanca, ${ }^{4}$ Francisco Sánchez de las Brozas (1523-1600). Asimismo afirmábamos que la de Alciato no era la única exégesis a los Emblemata utilizada y consultada por Vitoria para la composición de su obra, pues en el Theatro aparecen referencias a los comentarios de Claude Mignault, editados por primera vez en París en 1571 (Martínez Sobrino y García Román, 2020: 617). ${ }^{5}$

Explicábamos además que Vitoria recurría hasta en 133 ocasiones a la autoridad de Alciato porque el carácter ejemplarizante de sus emblemas se adecuaba al tono y naturaleza de la obra del franciscano (Martínez Sobrino y García Román, 2020: 617). ${ }^{6}$ Una auctoritas la del milanés a la que Vitoria apelaba de muy distintas y variadas formas, y con la que lograba enriquecer su mundo significativo (Compagnon, 1979: 76). ${ }^{7}$

En aquel entonces dividíamos las citas en dos grupos principales: A) Alciato como fuente asociada y B) Alciato autoridad única (Martínez Sobrino y García Román, 2020: 618-623). Dos grupos principales que subdividíamos a su vez en otros menores. De esta clasificación llamaban especialmente nuestra atención los supuestos del segundo grupo, tanto por su mayor variedad, como por la riqueza de las relaciones que se establecían entre los textos. Entre otras razones porque el mero hecho de la citación multiplica el número de distorsiones semióticas y semánticas (Morawski, 1970: 692). ${ }^{8}$ Así Alciato podía aparecer como autoridad indirecta, como noticia de la materia de los emblemas, etc.

De ese grupo, dábamos asimismo testimonio de casos únicos y originales, y mostrábamos, por ejemplo, que Baltasar corregía a Alciato en el emblema 70 por haber afirmado que Tereo había cortado la lengua a Progne cuando en realidad se la había seccionado a Filomela (Vitoria, 1620: 940-941); o veíamos cómo Baltasar descubría la razón por la cual el milanés se servía de una determinada figura en un emblema concreto, en nuestro caso el 98 (Vitoria, 1623: 531-532):

2. Bajo el título de "Tesoro..." o "Teatro...", muchos autores recopilaban todo el saber que tenían a mano sobre cualquier tema, y así, con las polyantheas, se convirtieron en las enciclopedias de la época (López Poza, 2000). Para una panorámica sobre los comentarios, cf. Céard, 1996.

3. Sobre la fecha de composición del mismo, cf. Merino Jeréz y Ureña Bracero, 2004.

4. «[...] y oyendo yo Retorica en Salamanca, al mas insigne hombre que en aquellos tiempos vuo en aquella facultad, que fue el Maestro Francisco Sanchez, Catedratico de propriedad de aquella Vniversidad [...]" (Vitoria, 1620: 807).

5. Para una historia de los comentarios de Mignault, cf. Vuilleumier Laurens, 2000: 145-171.

6. Tal vez la intención de Alciato era que sus emblemas no fueran más que juegos retóricos sin aspiraciones políticas o didácticas, pero lo cierto es que se acudió a ellos como modelos de moral, cf. Henebry, 2003 : 173.

7. La variedad de usos deja al descubierto ciertas contradicciones o paradojas en lo que por un lado el monje franciscano entiende como emblema y el funcionamiento de la relación pintura-palabra y, por otro, lo que refieren sus propios textos; para un ejemplo, cf. García Román y Martínez Sobrino, 2017.

8. En ninguna de ellas se produce la variante pura T1-T2, de la que Compagnon (1979: 78) afirma que está exenta de toda connotación. 
Andreas Alciato puso en compañia de la Fortuna al Dios Mercurio, sentado sobre vn pedestal quadrado, circunstancias opuestas a los demas Simulacros de la Fortuna. Porque todas sus figuras son estampas, y Hierogliphicos de la mutabilidad y inconstancia: y junto con esso de su poca prudencia, y aviso: todo opuesto ex diametro, a la otra pintura, porque Mercurio es Dios de la sabiduria y prudencia, como se dixo en el primer lib. deste Theatro. Lo segundo es estar sentado, que demuestra sossiego y quietud, que por esso disponen las leyes, que los juezes han de estar sentados para pronunciar las sentencias. Dando a entender el sossiego y cordura con que han de proceder. Iuntemos a esto la tercera cosa que es estar sentado sobre un pedestal quadrado, que como dize Pierio los Atenienses le pintauan assi: significando en esto la razon, y la verdad.

Asimismo, observábamos la ecfrasis del franciscano a los versos del emblema 137 (Vitoria, 1623: 118):

$\mathrm{Y}$ al fin se concerto, por gran suma de dinero delante de su hijo del Rey, llamado Phileo, con condicion, que esta tarea se auia de acabar en vn dia: à lo qual se quiso obligar Hercules. Y lo que hizo para mas breuedad, y mas limpieza: saco de madre al rio Alfeo, que corria cerca de alli, y endereçole y guiole à las cauallerizas, y assi en breues horas dio con su tarea al cabo: porque entro el rio muy furioso, y barrio todas aquellas inmundicias, que esso quiso dezir Alciato en la emblema ciento y treinta y ocho: Expurgat sordes.

Y así como destacábamos referencias como las señaladas, dábamos cuenta también de que, entre ellas, había dos muy llamativas, pues, Baltasar indicaba las posibles fuentes para sendos emblemas. Se trataba de dos citas recogidas en el libro dedicado a Venus, de las cuales, la segunda certificaba que Alciato imitaba un epigrama sito en Roma en su emblema 162 (Vitoria, 1623: 439-440):

Lilio Giraldo dixo que su madre se llamo Eunomia, y para prouarlo trae vnos versos, de vn Epigrama que esta en Roma, y entre los demas disticos trae este: Iupiter est genitor, peperit de semine Celi / Eunomia, et Veneris turba ministra fuit. / Iupiter engendro las Gracias bellas, / Eunomia las pario, celestial Diosa, / Y a Venus se las dan por sus donzellas. Y Andreas Alciato imito los versos de aquel Epigrama, donde dixo: Iupiter iis genitor, caeli de semine Diuas / Omnibus acceptas edidit Eunomia.

Mientras que la primera apuntaba a que el origen de los emblemas 154 y 155 (Vitoria, 1623: 452-453) se encontraba en la lectura y reinterpretación de un poema de Joachim Du Bellay:

Y en este mismo pensamiento se deuio de fundar quien dixo, que el amor, y la muerte auian trocado las armas, inaduertidamente. Y fue pensamiento de Ioachimo Bellatio, que lo trae en vna Epigrama el qual imito Andreas Alciato en el Emblema 154 y 155. Errabat socio Mors [in]iuncta Cupidine: secum / Mors pharetras, paruus tela gerebat Amor. / Diuertere simul, simul una et nocte cubarunt: / Caecus amor; Mors hoc tempore caeca fuit. / Alter enim alterius male prouida spicula sumpsit, / Mors aurata tenet, ossea tela puer. I Debuit inde senex qui nunc Acheronticus esse, / Ecce amat, et capiti florea serta parat.

Una traducción realizada por Alciato y que le brindó a Baltasar de Vitoria la ocasión de imitarlo mediante la composición de un soneto que ofrece en su texto (Vitoria, 1623: 453): ${ }^{9}$

9. La referencia la toma Baltasar del comentario de Claude Mignault, 1600: 543, quien ofrece la siguiente traducción al latín: "Mutarunt arma inter se Mors atque Cupido: / Hic falcem gestat, gestat at illa facem. / Afficit haec animum, corpus sed conficit ille. / Sic moritur iuvenis: sic moribundus amat. / Ut secat hic iugulos, oculos excaecat $\theta$ illa: / Illa ut amare docet, sic iubet iste mori, / Disce hinc, humanae quae sint ludibria vitae: / Mors thalamum sternit, sternit Amor tumulum. I Tu quoque disce tuas, Natura, invertere leges: / Si pereunt iuvenes, depereuntque senes».

IMAGO, NúM. 13, 2021, 25-35 
No traduxo esto al pie de la letra, sino solamente el sentido, del qual hize este Soneto:

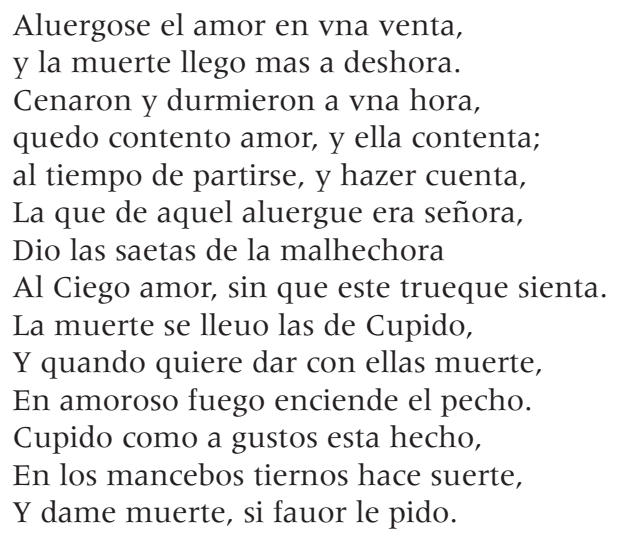

Llevados por la afirmación de que él mismo había compuesto una segunda revisión del poema original del poeta francés, pensamos, erróneamente, que, si no todas, al menos muchas de aquellas traducciones de los emblemas de Alciato sin una autoría reconocida podían ser de Baltasar (Martínez Sobrino y García Román, 2020: 628 en nota). Algo que hemos descubierto no es tal, pues en la $2^{\mathrm{a}}$ parte aparecen al menos cinco composiciones cuya autoría no se señala, y ciertamente no es suya. Hablamos de tres traducciones de otros tantos epigramas extraídas de la obra de Francisco Vélez de Arciniega, Boticario del Cardenal y Arzobispo de Toledo Bernardo de Sandoval y Rojas, Historia de los animales mas recebidos en el uso de la medicina y donde se trata para lo que cada uno entero o parte de él aprovecha y de la manera de su preparación, Madrid, 1613.

Tal vez sorprenda que contenidos de obras en apariencia tan alejadas se entreveren a tal punto entre sí; al fin y al cabo, ambas pertenecen a géneros que en apariencia tienen poco o nada en común. Sin embargo, en la época no se percibían distantes, pues tanto los Teatros como las Historias compartían muchos rasgos, que asimismo los englobaban junto a otra multitud de géneros en obras de saber para-enciclopédico. ${ }^{10}$ Esa es la razón de que aparezcan junto a los Tesoros, cuya definición, según el Diccionario de Autoridades (Tomo VI: 1739), es «metaphoricamente vale, depósito, suma, ò compendio de noticias, ò cosas dignas, y estimables del Lat. Thesaurus». Una enunciación próxima a la del término Historia, que "se llama tambien la descripción que se hace de las cosas naturales, animales, vegetables, minerales, \&c.» y no solo refiere la "[r] elación hecha con arte: descripción de las cosas como ellas fueron por una narración continuada y verdadera de los sucessos más memorables y las acciones más célebres». ${ }^{11}$ Definiciones muy similares, por otra parte, al concepto de Teatro que se acuña a partir de Camilo Delminio y su Idea del teatro (1550), y que tendrá como consecuencia que a partir de este momento por Teatro se entienda un tipo de obra que aspira a «dar orden al orden», esto es, que anhela descubrir el orden subyacente más allá de la variedad del mundo y sistematizarlo dentro de un esquema de categorías lógicas (Cherchi 1993: 89). Un escrito, por tanto, que contiene el mundo de forma ordenada, al igual que lo hace una enciclopedia; pero que, a diferencia de esta, su taxonomía es lógica, como sucede con la Historia y los Tesoros.

10. Nos servimos aquí del término utilizado por Cherchi (1993: 90).

11. Diccionario de Autoridades - Tomo IV (1734), segunda acepción. 
Por otro lado, el Diccionario de Autoridades (1739: Tomo VI) en su quinta acepción determina Theatro de la siguiente forma: «Metaphoricamente se llama el lugar, donde alguna cosa està expuesta à la estimacion, ò censura universal. Dicese freqüentemente el theatro del Mundo. Lat. Theatrum. Publicum, ci». Una definición que, en principio, engloba bajo su paraguas cualquier tipo de escrito, pues todos se exponen al juicio ajeno, pero que, pensamos, es aplicable en particular a Vélez de Arciniega. No solo por la obra en sí, sino porque su autor se muestra especialmente preocupado por la valoración que se haga de ella. ${ }^{12}$

Con todo, como podrá apreciarse a continuación, aparte de los parecidos teóricos mencionados, estos escritos mantienen otras correspondencias textuales cuyos objetivos los aúnan. Así sucede con:

1. La transmisión de toda la ciencia encerrada en sus respectivas artes. Como apunta Baltasar en la segunda parte de su Teatro (1623: epístola al lector):

Mas añadi à este Prologo, lo que falto de advertirse en el primero, y es que lo que en estos treze libros se trata, es quien fue cada Dios, sus padres, y sus hijos, sus Metamorphoseos, conversiones y ensayos. Los Templos que les fueron consagrados, las Ciudades en que fueron adorados y reverenciados. Que si bien es verdad en toda la Gentilidad fueron respetados, y adorados con Religion y culto sancto estos Dioses mayores, cada uno en particular tenia Ciudades y Reynos donde con mayor veneración era estimado y respetado. Como nos sucede con mayor veneracion era estimado y respectado. Como nos sucede con mayor acierto a los Christianos, que aunque a todos los Sanctos en común reverenciamos y adoramos, ay Ciudades y Reynos donde se tiene particular devoción con cada uno dellos. Tambien se trata en estos libros de las aves animales arboles y plantas que à cada Dios son dedicadas, con todas sus propiedades essencias, y virtudes.

\section{Vélez de Arciniega (1613: privilegio real):}

Por cuanto por parte de vos Francisco Velez de Arciniega Boticario, [...], no fue hecha relación que aviadés compuesto tres libros tocantes a vuestra falcultad, los quales se avian impresso con licencia nuestra; y agora últimamente aviades compuesto otro, intitulado, De las Aves, Pezes, y Conchas, recebidas en el uso de la Medicina, y de la manera de su preparación: el cual era de mucha utilidad y provecho, no solamente para los Boticarios, Medicos, Cirujanos, sino para toda la Republica, por aver escritos en el muchos y muy varios remedios para diversas enfermedades de quien podrian usar los susodichos, y los vecinos de los pueblos, que por ser pequeños, ò por tener poca possibilidad carecerían dellos.

2. La utilización de todas las fuentes a su alcance:

Así, Baltasar de Vitoria (1623: epístola al lector):

Fuera de esto se trata de las imágenes pinturas y estatuas levantadas y consagradas a estos Dioses, que es lectura muy curiosa y entretenida, y aun muy trabajada рогque para favorecer el intento, se han visto muchos libros, y muy exquisitos, ${ }^{13}$ como se podra ver en el discurso destos tratados: $[\ldots]$.

12. Esta afirmación nos hace presumir que alguna de las obras anteriores fue criticada negativamente, aunque no hemos encontrado prueba alguna de ello.

13. Diccionario de Autoridades -Tomo III (1732) EXQUISITO, TA. adj. Singular, peregrino, extraordinario, raro, y de particular aprécio y calidad. Es tomado del Latino Exquisitus, que significa lo mismo. Latín. Singularis.

IMAGO, NÚM. 13, 2021, 25-35 
Y Vélez de Arciniega (1613, yambo dedicatorio): Opus hoc venustum tamque plenum flosculis / Hucusque latuit involutum nubibus/ Utpote vigiliis se invidens mortalium; o más adelante, en el comienzo del primer capítulo al libro de peces (1613: 396):

El primer inventor de la música (según dice Plinio) fue Amphion, y son tan maravillosos us efectos que no me parecio ageno el encomendar a la pluma algunos dellos, y extretexer con los verdaderos algunos Poeticos para que sirvan de algún entretenimiento al lector.

3. Ser de utilidad para un público amplio, cuanto mayor, mejor, como muestra que no se le exija estar cultivado en lenguas clásicas:

Así lo afirma Baltasar de Vitoria (1623: epístola al lector) y, añade, que por ello lo explica todo en el modo más sencillo y claro posible:

[...] los quales no van dispuestos con estilo poético, ni affectado (como algunos pensaron que fueran) porque esto no es de contar historias, las quales se suelen siempre trazar con estilo llano y comun, que estos libros no sirven de mas, que de dar mano y aparejo à los que quieren tratar de Poesia, para que hallen las historias y Fabulas recogidas y dispuestas, para poder saber con facilidad y claridad, sin andar rebolviendo libros de latinidad, ni de otras lenguas extrangeras. Que no todos los Poetas tienen noticia de la lengua Latina con essas ventajas, que por si solos puedan alcançar a saber todo esto, y quando fepan todas essas lenguas, por lo menos, no les daña el hallarlo en la suya propria, y que otro se lo aya trabajado. Epístola al lector.

Al igual que Vélez de Arciniega (1613: privilegio real):

[...] el cual era de mucha utilidad y provecho, no solamente para los Boticarios, Medicos, Cirujanos, sino para toda la Republica, por aver escritos en el muchos y muy varios remedios para diversas enfermedades de quien podrian usar los susodichos, y los vecinos de los pueblos, que por ser pequeños, ò por tener poca possibilidad carecerían dellos.

Un texto este que recoge la idea ya expresada por el propio autor en su anterior y predecesor Libro de los quadrupedes y serpientes terrestres recebidos en el uso de la Medicina y de la manera de su preparación, Madrid, 1597, donde su epístola al lector dice:

Despues de aver venido a esta Corte acordome que no nos es concedido gastar la vida en ociosidad, [...]; para satisfacer en parte esta deuda, me parecio ocupar algunos ratos en escrevir esta obra, y sacarla a la luz en nuestra vulgar, por ser no solamente para boticarios y medicos acomodada, mas para otros muchos ingenios, que gustan de saber de historias de animales, $[\ldots]$.

Como puede apreciarse, ambos autores, que persiguen un público amplio al que no se le exige mayor capacitación que la de leer en castellano, componen en dicha lengua las partes originales de sendas obras, al tiempo que vierten también a ella las citas tomadas de autores clásicos y modernos (tanto latinos como griegos). ${ }^{14}$ Asimismo, confiesan haber redactado sendas composiciones con un muy preciso objetivo en mente. En el caso de Baltasar, que otros poetas, predicadores, etc. extraigan perlas de autoridad para sus composiciones; en el de Vélez de Arciniega, que aquellos que las necesiten obtengan remedios para distintas enfermedades y, en un segundo lugar, que los curiosos de la naturaleza conozcan el mundo

14. Ambos autores entretejen a modo de emblemas citas clásicas en su lengua original, pero ambos ofrecen siempre el sentido de las mismas. Si no, en traducción directa, en paráfrasis. 
animal. Para lo cual, reconocen, han consultado y empleado gran número de libros de valor extraordinario, tanto prosísticos como versificados.

Y entre la multitud de autores a los que han acudido y citado uno y otro, se encuentra aquel que nos interesa, el abogado milanés Andrea Alciato, quien, con sus Emblemata, se había convertido en una de las autoridades más relevantes del momento. ${ }^{15}$ Vélez de Arciniega no lo utiliza por razón de sus conocimientos zoológicos, pues en tal caso todas las referencias faunísticas coincidirían con los animales respectivos en los capítulos correspondientes, con lo que no se producirían discrepancias como, por ejemplo, la que ocurre con el emblema 170, «Post mortem formidolosi», que aparece tanto en el capítulo dedicado al lobo como en el del Águila Real. ${ }^{16} \mathrm{Al}$ contrario, Alciato es fuente para otro tipo de saberes, que, como se ha señalado, poseen un valor más ético. Un rasgo este último que se ve reforzado por la verdadera fuente de la que nuestro boticario extrae las perlas del milanés, los comentarios de Sánchez de las Brozas. ${ }^{17}$ Obra y autor cuya autoridad no reconoce nunca -algo habitual en la época con este tipo de obras (López Poza, 2000: 193-194)-, tal vez por no ser el humanista especialista en el mundo animal.

No sucede lo mismo en el caso de Baltasar de Vitoria, quien confiesa haber consultado los comentarios a Alciato del Brocense, así como los de Claude Mignault. Sin embargo, sabemos que no fueron, ni mucho menos, las fuentes únicas por las que este autor llegó a su obra, pues, aparte de que fuera probable que contara con alguna edición de los Emblemata, es seguro que utilizó la Historia de los animales mas recebidos de Vélez de Arciniega ${ }^{18}$ para componer la Segunda parte del Theatro, que constituye una importante mina de la que surtirse para tratar de las "propiedades, y virtudes» (Baltasar, 1623: epístola al lector) de los animales terrestres, aves y peces relacionados con las divinidades paganas. Paradójicamente, con Vélez de Arciniega y Baltasar sucede lo mismo que con el Brocense y Vélez de Arciniega, que, para hablar de Alciato, el segundo utiliza al primero sin su reconocimiento expreso, como se puede comprobar en las cinco traducciones que Baltasar ofrece de los emblemas de Alciato. ${ }^{19}$

15. De hecho, lo son todos los libros de emblemas, como apunta López Poza (2000 y 2005). En cuanto al éxito de Alciato no hay más que atender a las 210 ediciones que se hicieron de su obra entre 1531 y 1551, cf. Mino, 2009: XIII-XXV. Como antecesor de Vélez de Arciniega, destaca Gessner quien en su obra zoológica sólo cita como emblemista a Alciato (García Arranz, 2000: 801-802).

16. En más de una ocasión Vélez de Arciniega refiere un emblema cuya relación con el animal del capítulo en cuestión se establece por constituir este el símbolo del concepto. Lo que ocurre, por ejemplo, con el emblema 11 «Silentium» y el ansarón; o el emblema 194, "Pietas filiorum in parentes» y la cigüeña; o el 72, "Luxuria», y el gorrión; o el 44, "Simulacrum spei», y la corneja. Por ello sucede también que se citen emblemas en los cuales se representan pecados capitales como la Gula -emblemas 90, 94 y 98-, la Avaricia -emblemas 84 y 85-, la Lujuria -emblema 72-; o que un solo capítulo recoja más de un emblema, por ejemplo, el 15, 21, 30, 38, 44, 60, 66, 84, $85,88,168,194 ; 0$, al contrario.

17. La razón principal por la que pensamos que Vélez de Arciniega toma a Alciato desde el Brocense es que al tratar del Águila Real y citar el emblema 170 (1603: 236) apunta inimicitia post mortem etiam durans para indicar que la enemistad es eterna entre animales enemigos en vida. Una idea recogida en el índice de los comentarios de Sánchez de las Brozas a Alciato en la entrada correspondiente al emblema 170: Animalium inimicitiam post mortem. A lo que se suma que en el comentario al emblema encontremos en un ladillo in animalibus inimicitia post mortem y en el cuerpo credunt Physici, etiam post mortem durare odia illorum quae natura sunt inimica $(1573: 474)$.

18. Baltasar cita los siguientes 28 emblemas de Alciato en su segunda parte: 1, 8, 11, 17, 19, 23, 24, 27, 38, 40, 52, $58,82,92,98,105,106,118,125,137,138,141,162,177,180,185,187,192$. Reconoce utilizar a Claude Mignault en los siguientes: 11, 19, 22, 28, 40, 58, 72, 77, 98/112, 118, 123, 137, 138, 145, 157,168, 187. Y se sirve de Vélez de Arciniega para 11, 17, 38 y 40. Como puede apreciarse, los emblemas y las fuentes se solapan, con lo que es complicado saber qué se toma de quién (excepto las traducciones de Vélez de Arciniega). Con todo, no es ese nuestro objetivo aquí, por lo que nos limitamos a enumerar sus posibles fuentes.

19. El criterio de ordenación se corresponde con el orden numérico ascendente de los emblemas de Alciato.

IMAGO, NÚM. 13, 202I, 25-35 
El primero sería el emblema 11, «Silentium», que Vélez de Arciniega cita a propósito del ansarón y su cualidad para representar el silencio (1613: 310-311):

Oxala callassedes dixo el bendito Iob, y seriades tenidos por sabios. De aqui sospecho yo que tuvo ocasión el emblema de Alciato intitulado Silentium, donde aviendo pintado una figura de un sabio, con el dedo sobre los labrios dize la letra en nuestra vulgar traduzida:

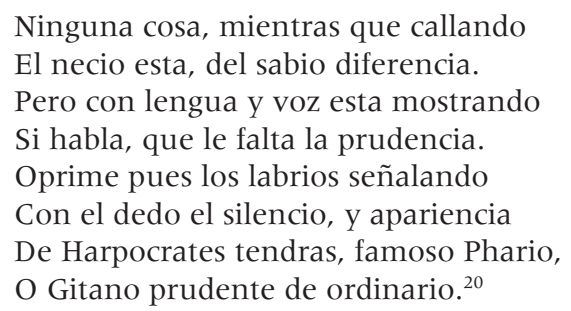

El segundo de los poemas es el que Alciato compone para el emblema 17, «Quid excessi, quid amissi?», y que Veléz de Arciniega traduce al hablar de las grullas y de la prudencia por ellas encarnada (1613: 306):

Desta prudencia de que usan las Grullas, tomò Alciato ocasión para hazel el Emblema intitulado: Quid excessi, quid amissi? donde en la letra del, alabando un consejo de Pythagoras, dize:

$$
\begin{aligned}
& \text { Samo famoso autor italiano } \\
& \text { En verso breve encierra su decreto: } \\
& \text { Dandonos por consejo que ante mano } \\
& \text { De poner los negocios en effeto, } \\
& \text { Los consultemos bien, y es caso llano } \\
& \text { Le tomò de las grullas, que en secreto } \\
& \text { Las piedras toman, en lugar de lastre, } \\
& \text { Para passar las aguas sin desastre. }
\end{aligned}
$$

El tercero de los textos de Vélez de Arciniega que utiliza Baltasar es el que corresponde a la corneja y a la concordia por ella representada en el emblema 40, "Concordiae symbolum» (Vélez de Arciniega, 1613: 256):

La historia destos cuenta Iustino en el ultimo libro de donde se comprueva todo lo que dicho es en las Cornejas, de las quales escrivio otro Emblema el dicho Alciato, intitulado Concordiae symbolum en el qual, aviendo pintado estas aves dice:

$$
\begin{aligned}
& \text { De la concordia son viva pintura } \\
& \text { Las cornejas, en quien con gran fineza, } \\
& \text { Amor y lealtad florece y dura. } \\
& \text { Promete a el Reyno grande fortaleza } \\
& \text { La concordia, y muy grande desventura } \\
& \text { La discordia, do habita la flaqueza } \\
& \text { Esta a los Reyes los sus ceptros quita, } \\
& \text { Pueblos y Capines debilita. }
\end{aligned}
$$

20. El último verso es creación propia, seguramente para poder realizar la octava real. No es el único cambio, pues Alciato habla a una $3^{\mathrm{a}}$ persona, mientras que Vélez de Arciniega lo hace a una $2^{\mathrm{a}}$. 
El cuarto se dedica al alción, ave que simboliza la paz y al que Alciato refiere en su emblema 178, «Ex pace ubertas» (Vélez de Arciniega, 1613: 370):

Por symbolo de la paz pone Alciato a el ave Alcyon, porque criando en el mayor rigor del Invierno, en todo el tiempo que haze le nido que pone y empolla los huevos, saca y cria a sus hijos, està el Mar muy sosegado. El titulo del Emblema es Ex pace ubertas y la letra buelta en nuestro vulgar suena (soneto):

De proceras espigas diestramente

Texe guirnaldas bien ataviadas,

$\mathrm{Y}$ vayan en circuito rodeadas

Con pampanos de vid curiosamente.

Symbolo son aquestos aparentes,

A los nidos de Alcyones asseados,

Aves, que mientras crian embarcadas,

Està tranquilo el mar perpetuamente.

De aquí una conjetura muestra aguda,

Que el Rey que las imita, es avisado

(Pues cosa alguna no le altera o muda)

Que haze al año fertil y colmado.

$\mathrm{Y}$ a Baco y Ceres, sin alguna duda,

Que alegres gozen del quieto estado.

Y el quinto y último, tomado para su primera parte, es el dedicado al cisne y su simbolización de la figura del poeta (Vélez de Arciniega, 1613: 354):

Acordose tambien desto Alciato en el Emblema intitulado: Insignia Poetarum, cuyas palabras son las siguientes:
Ay algunos que traen en los escudos Aguilas, o Leones, o Serpientes
Por divisas: mas aquestos sañudos
Animales no son pertenecientes
A los de los Poetas, porque agudos,
Y humanos han de ser entre las gentes.
Pinten al Cisne, a Phebo consagrado,
Por Rey en todo tiempo reputado.

Resulta hasta cierto punto curioso que Baltasar de Vitoria no reconozca la fuente de las traducciones, no tanto porque, como se ha señalado, no fuera costumbre en la época, sino por cuanto él mismo ofrece el siguiente testimonio (Baltasar de Vitoria, 1623: 23):

Cerca de lo qual es notable historia la que cuenta un Autor fidedigno, que se halló presente a la pendencia de dos gallos, en el Reyno de Inglaterra en tiempo del desdichado Enrique VIII. Dize este Autor, que en Londres estaba fundado un Amfiteatro muy sumptuoso, a manera de Coliseo, destinado solamente para las peleas de estas aves, y en torno dèl avia muchas caponeras, pertenecientes a muchos Principes del Reyno. [...]. Y los dos que viò este Autor, diz, que en poniendolos en la coluna, que era la estacada, o palenque de su contienda; [...]»

Texto junto al cual un ladillo, que reza «Francisco Velez de Arciniega (Libro 3, de la Historia de los animales, c. 8)", sugiere que su autor ha tomado la referencia de la Historia de los animales mas recibidos de Vélez de Arciniega (1613: 297-298). 
Cierto es que llama la atención que Baltasar de Vitoria califique a Vélez de Arciniega de «autor fidedigno» y que posteriormente, cuando utiliza sus traducciones de Alciato, no lo mencione. No estamos sugiriendo que hubiera mala voluntad por parte del monje franciscano, pues, como se ha apuntado, era costumbre actuar así. Hay que entender, creemos, que lo que sucede es que "fidedigno" sirve para certificar que la anécdota goza de credibilidad absoluta según su criterio; entre otras cosas, porque certifica lo apuntado por otra fuente autorizada, el Pedazio Dioscórides Anazarbeo, 1555, de Laguna (Vélez de Arciniega, 1613: 297):

Laguna dize: Es el Gallo un animal ambicioso, feroz, sobervio, y en tanto grado animoso, que con el Aguila rostro a rostro, muchas vezes se atreve a pelear. Demas desto es muy amigo de despartir, sin querer jamas ser despartido: y quando vee alguna vez a otros dos contrastando, se mete en medio, y no pudiendo reconciliarlos, favorece siempre a la parte mas flaca. Conoci la gran virtud y valor de los Gallos, en el año de noventa y tres en Londres en Inglaterra, adonde el Rey Henrique Octavo de aqueste nombre [...].

Como puede observarse en este segundo estudio acerca de la función subsidiaria de la emblemática en la obra mitológica de Baltasar de Vitoria, los caminos por los que transita son mucho más numerosos y sorprendentes de lo que a primera vista se pudiera suponer. La amplia gama de referencias con que el monje franciscano completa su obra abarca desde la noticia directa hasta aquella que se obtiene de obras que en principio poco o nada tienen en común. Un ejemplo más que hace patente la naturaleza referencial intra- y extra- textual de la literatura en general, y que, como vemos, se agudiza en el caso de la poesía, un género especialmente caracterizado por su capacidad de independizarse de su contexto interpretativo original y de dotarse, en consecuencia, de gran polisemia.

\section{BIBLIOGRAFÍA Y FUENTES}

Céard, J. [1996]. "De l'encyclopédie au commentaire, du commentaire à l'encyclopédie: le temps de la Renaissance", en R. Schaer (ed.), Tous les savoirs du monde: encyclopédies et bibliothèques de Sumer au XXe siècle, Paris, BNF, 164-9.

Compagnon, A. [1979]. La Seconde main or la travail de la citation, Paris, Seuil.

García Arranz, J. J. [2000]. "Las enciclopedias animalísticas de los siglos XVI y XVII y los emblemas: Un ejemplo de simbiosis» en Mínguez, V. (ed.), Del libro de emblemas a la ciudad simbólica. Actas del III Simposio Internacional de Emblemática Hispánica, vol. 2, Universitat Jaume I, Castelló, 793-819.

García Román, C. y Martínez Sobrino, A. [2017]. "On the Presence of Alciato's Emblems in the Work of Baltasar de Vitoria, Disciple of Francisco Sánchez de las Brozas», en B. Taylor y A. Coroleu (eds.), Brief Forms in Medieval and Renaissance Hispanic Literature, Cambridge Scholars Publishing, Newcastle upon Tyne, 168-188.

Henebry, Ch. [2003]. «Figures of Speech: The Emblematum Liber as a Handbook of Rhetorical Ornaments», Neophilologus 87, 173-191.

López Poza, S. [2000]. «Los libros de emblemas como 'tesoros' de erudición auxiliares de la 'Inventio'», en R. Zafra y J. J. Azanza (eds.), Emblemata Aurea. La emblemática en el Arte y la Literatura del Siglo de Oro, Madrid, Akal, 236-279. 
López Poza, S. [2005]. "La difusión y recepción de la Antología Griega en el Siglo de Oro», en B. López Bueno (dir.), En torno al canon, aproximaciones y estrategias: VII Encuentro Internacional sobre Poesía del Siglo de Oro, Sevilla, Universidad de Sevilla, 15-68.

Martínez Sobrino, A. y García Román, C. [2020]. «La emblemática subsidiaria de la mitología didáctica: Alciato en el Theatro de los Dioses de la Gentilidad I» en López Calderón, C. Monterroso Montero, J. M. (eds.), El Sol de Occidente. Sociedad, textos, imágenes simbólicas e interculturalidad, Adavira editora, Santiago de Compostela, 616-630.

Memorial University of Newfoundland [2005]. Alciato's Book of Emblems. The Memorial Web Edition in Latin and English, <https://www.mun.ca/alciato/index.html>, consultado $10 / 02 / 2021$.

Merino Jerez, L. y Ureña Bracero, J. [2004]. «On the date of Composition of El Brocense's Commentaria in Alciati Emblemata», Emblematica, 13, 73-96

Mignault, C. [1600]. Andreae Alciati. V. C. Emblemata. Cum Claudi Minois ad eadem commentariis o notis Posterioribus [...], Lugduni, Apud Haeredes Guilielmi Rovillii, <https://goo.gl/ u7mypg $>$, consultado 10/02/2018.

Mino, G. [2009]. Andrea Alciato. Il Libro degli Emblemi secondo le edizioni del 1531 e del 1534, Adelphi Edizioni, Milano.

Morawsky, S. [1970]. "The basic functions of quotation», en J. Greimas (ed.), Sign, Language, Culture, Signe, Langage, Culture, Znak, Jezyk, Kultura, ЗНАК, ЯЗЫК, КУЛЬТУРА, Paris, Mouton, The Hague, 690-705.

Serés, G. [2003]. "El enciclopedismo mitográfico de Baltasar de Vitoria», La Perinola 7, 397-421.

Santamaría Hernández, $M^{a}$. T. [2005]. «Textos médicos antiguos y tradición literaria en el Libro de los quadrupedes, y serpientes terrestres del boticario Vélez de Arciniega (1597)", A. Alvar Ezquerra (Coord.), Actas del XI Congreso Español de Estudios Clásicos, vol. III, Madrid, 585-594.

Sanchéz de las Brozas, F. [1573]. Comment. in And. Alciati Emblemata: nunc denuò multis in locis accurate recognita et quamplurimis figuris illustrata Lugduni: apud Guliel. Rouillium, https:// books.google.es/books?id=mCBXAAAAcAAJghl=es, consultado 10/02/2021.

Cherchi, P. [1993]. «Enciclopedias y organización del saber de la Antigüedad al Renacimiento", Rodríguez Cuadros, E. (ed.), De las Academias a la Enciclopedia: El Discurso del Saber en la Modernidad, Alfons el Magnànim, Valencia, 71-94.

Velez de Arciniega, F. [1613]. Historia de los animales más recibidos en el uso de la medicina, donde se trata para lo que cada uno entero o parte de él aprovecha y de la manera de su preparación, Madrid. https://books.google.es/books?id=p4NAAAAAcAAJ\&hl=es, consultado el $10 / 02 / 2021$.

Vitoria, B. de [1620]. Primera Parte. Theatro de los Dioses de la Gentilidad, Salamanca, en casa de Antonia Ramírez, <https://goo.gl/JtF2yR>, consultado 10/02/2021.

Vitoria, B. de [1623]. Segunda Parte del Theatro de los Dioses de la Gentilidad, Salamanca, en casa de Diego Cussí, <https://goo.gl/z8H7ip>, consultado 10/02/2021.

Vuilleumier Laurens, F. [2000]. La Raison des Figures Symboliques a la Renaissance et a l'Âge Classique. Etudes sur les fondements philosophiques, théologiques et rhétoriques de l'image, Droz, Genève. 
